\title{
Comparative Study of Prevalence of Early Initiation of Breast Feeding, Its Enablers and Impeders
}

Varsha Mahesh Vaidya ${ }^{1}$, Prakash Prabhakarrao Doke ${ }^{2}$, Arvinder Pal Singh Narula ${ }^{3}$, Girija Narendrakumar Wagh ${ }^{4}$, Tushar Madhav Panchanadikar ${ }^{5}$, Archana Vasantrao Patil ${ }^{6}$

${ }^{1}$ Professor, Department of Community Medicine, Bharati Vidyapeeth Deemed University Medical College, Pune, India; ${ }^{2}$ Ph.D., Department of Community Medicine, Bharati Vidyapeeth Deemed University Medical College, Pune, India; ${ }^{3}$ Assistant Department of Community Medicine, Bharati Vidyapeeth Deemed University Medical College, Pune, India; ${ }^{4}$ Professor Department of Obstetrics and Gynecology, Bharati Vidyapeeth Deemed University Medical College, Pune, India; ${ }^{5}$ Professor and Head Department of Obstetrics and Gynecology, Bharati Vidyapeeth Deemed University Medical College, Pune, India; ${ }^{6}$ Director Health Services, Government of Maharashtra, Pune, India.

\begin{tabular}{|c|c|c|c|c|c|c|c|c|}
\hline Abstract & Introduction & Methodology & Results & Conclusion & References & Citation & \multicolumn{2}{|c|}{ Tables / Figures } \\
\hline \multicolumn{9}{|c|}{ Corresponding Author } \\
\hline \multicolumn{8}{|c|}{$\begin{array}{l}\text { Dr. Prakash Prabhakarrao Doke, Professor Department of Community Medicine, BVDU Medical } \\
\text { College, Satara Road, Dhanakawadi, Pune., India - } 411043 . \\
\text { E Mail ID: prakash.doke@gmail.com }\end{array}$} & 回语回 \\
\hline
\end{tabular}

\section{Citation}

Vaidya VM, Doke PP, Narula APS, Wagh GN, Panchanadikar TM, Patil AV. Comparative Study of Prevalence of Early Initiation of Breast Feeding, Its Enablers and Impeders. Indian J Comm Health. 2021;33(1):56-64. https://doi.org/10.47203/IJCH.2021.v33i01.008

Source of Funding: Nil Conflict of Interest: None declared

\section{Article Cycle}

Received: 30/11/2020; Revision: 05/01/2021; Accepted: 08/02/2021; Published: 31/03/2021 This work is licensed under a Creative Commons Attribution 4.0 International License.

\section{Abstract}

Background: In India the proportion of early initiation of breastfeeding is hovering around $50 \%$ and the proportion of cesarean deliveries is increasing substantially. Objectives: To compare the prevalence of early initiation of breastfeeding (EIBF) among cesarean and vaginally delivered women in hospitals in Pune District, Maharashtra State, India and to measure any association between EIBF and various socio-demographic, maternal and fetal factors. Methods: This was a multi-site study conducted in 13 selected hospitals in Pune District in 2017-18. Pune District by population is the fourth largest in India. All women delivered by cesarean section in these hospitals and an equal number of age and parity matched vaginally delivered women were enrolled. They were interviewed before discharge by obstetricians or nurses under the supervision of obstetricians, using a structured, validated tool. The data were analyzed by using Statistical Package for Social Sciences, version 25. Results: In each group, 1,556 women were enrolled. The prevalence of EIBF was $81.5 \%$ and $63.6 \%$ among vaginally and cesarean delivered women. There was a significant association between EIBF and the place of residence, mode of delivery, gestational period, parity, and presence of some disease. Residence in the rural area was the strongest enabling factor with an adjusted odds ratio of 29.6 (95\% C.I.; 18.7-46.9) whereas cesarean section, preterm delivery and first para were impeding factors. Conclusions: Among institutional delivered women EIBF was about $70 \%$. Health care workers need to strongly promote EIBF awareness, especially among women from urban areas, and undergoing cesarean section.

\section{Keywords}

Breastfeeding; Mode of delivery; Rural; Urban; Gestation; Parity 


\section{Introduction}

Provision of mother's milk to the newborn within one hour of birth is termed as early initiation of breastfeeding (EIBF). It ensures receipt of colostrum which boosts the immune system of the newborn. It is the easiest, cost-effective and life-saving intervention for the health of the newborn. Numerous studies at diverse places have reiterated the effect of early initiation of breastfeeding on childhood mortality, especially neonatal mortality. $(1,2,3)$ The risk of neonatal mortality due to nonpracticing of EIBF and delaying it further may be as high as three to four times. $(1,2)$ EIBF may reduce $44 \%$ risk of neonatal mortality. (4) It even reduces the risk among low birth weight babies who are vulnerable.(5) The annual number of neonatal deaths ( 0.75 million) in India is the highest for any country. (6) Early initiation of breastfeeding is certainly one of the effective strategies for preventing neonatal deaths. (4) ElBF shows an increasing trend in all states. In the seven states of India having high burden of neonatal mortality, the overall rate of EIBF has increased from 12.5\% in 2006 to $34.4 \%$ in 2014. (4) EIBF in Maharashtra during $2019-20$ as per the latest survey was $53.2 \%$. (7) It is usually observed that after cesarean section the initiation of breastfeeding is delayed. In ten years from 2005-06 the rate of cesarean section in India has doubled from 8.5 to $17.2 \%$. (8) In $2019-20$ in Maharashtra it has reached to about 25.\%. (7) Globally also rate of cesarean sections has increased from $13 \%$ in 2005 to $20 \%$ in 2017. (9) In October 2018, Lancet has published a series, advocating optimization of lower segment cesarean sections. The rising cesarean sections may pose risk to the universalization of EIBF. Although most of the studies confirm that cesarean section is one of the barriers for initiation of breastfeeding, effect of cesarean section on EIBF is not conclusive. Both maternal factors like parity, mode of delivery, body mass index, smoking, breast problems, surgery, illness, psychological and behavioral factors as well fetal characteristics like gestational age, weight at birth, intrinsic disease, suckling ability, etc. have been closely associated with breastfeeding initiation. (2)

\section{Aims \& Objectives}

To compare the prevalence of EIBF among cesarean and vaginally delivered mothers in hospitals in Pune District, Maharashtra State, India and to study any association between EIBF and various socioeconomic, maternal/fetal factors.

\section{Material \& Methods}

Study Setting: The study was carried out in the Pune district having a 9,429,408 population. There are six medical college hospitals, one district general hospital, five sub-district hospitals, one women hospital, and 20 rural hospitals (community health centers) in the district. There are two Municipal Corporations, each having one tertiary care hospital. Sampling: This study was a part of a larger project wherein women were enrolled to assess postpartum morbidity. We confirmed the adequacy of the sample size as given below. The required sample size for estimating prevalence using standard the formula [ $\left.n=Z^{2 *} p^{*}(100-p) / d^{2}\right]$ and by assuming a prevalence of EIBF $54.8 \%$ in Pune district (10), with 95\% confidence level and allowable difference of $2 \%$ was 2,477 . Estimated sample size was only 11 , using formula, $\left[\mathrm{n}=(Z \alpha / 2+Z \beta)^{2} *[(\mathrm{p} 1(1-\mathrm{p} 1)+\mathrm{p} 2(1-\mathrm{p} 2)) /(\mathrm{p} 1-\right.$ $\mathrm{p} 2)^{2}$ ] for detection of $51 \%$ (65-14\%) difference as observed in one study. (11)

This study was conducted in 13 selected public hospitals (excluding one). The details are given in (Figure 1). The selection of study centers was based on a criterion of conducting more than five cesarean sections per month. All non-teaching government hospitals fulfilling this criterion were included and from teaching hospitals, one from government and one from private were included. All women, delivered by cesarean section in these hospitals, during the enrolment period, were included in the 'study group'. An equal number of age ( +5 years) and parity matched women delivered vaginally in the same hospitals during similar enrolment period were included in the 'comparison group'.

Inclusion and exclusion criteria: All women who had undergone cesarean section/vaginal delivery and resident of the Pune district were included. Women with serious psychiatric illness, immediately transferred to other institutions or who could not speak English, Hindi, or Marathi were excluded.

Data collection: Enrollment was carried out from 1st September 2017 to 31st March 2018. Written informed consent was obtained from all the study participants before interviewing them. A structured tool was jointly prepared by all investigators. It was validated, pretested, and translated into the local language (Marathi). It had three sections, 'demographic information', 'obstetric history', and 
'early initiation of breastfeeding'. One day training was given to a team of obstetrician or medical officer, the in-charge nurse of the postpartum ward from each selected hospital and from teaching hospitals one professor, post-graduate senior residents, and post-graduate students from the obstetrics and gynecology department. Among the trained members one 'site coordinator' was identified for each site for the collection of data. The women were interviewed 24-48 hours after the delivery and all information was sought definitely before discharge from the hospital. Additional information was collected from case records.

Data analysis: Forms were collected and checked for completion and accuracy at individual sites. Then at the nodal center the data entry operators entered the data under the supervision of the project coordinator. The project coordinator cross-checked the received forms and if needed obtained the required information by calling the site coordinator or the woman. The data was analyzed using Statistical Package for the Social Science Version 25. The Chi-square test was applied to establish the association between various variables. Appropriate adjusted odds ratios were calculated. P-value $<0.05$ was considered statistically significant.

Ethics Statement: Institutional Ethics Committee's (ECR/313/Inst/MH/2013/RR-16) approval was obtained before starting the study.

\section{Results}

A total of 3, 112 women (1,556 from each arm) participated in the study. Women having stillbirths among singleton pregnancies were not interviewed. The data about all the variables like age, education, occupation and urban-rural location, etc. could not be obtained from some women; however, the missing proportion was less than $10 \%$ excepting about education. The overall proportion of women initiating breastfeeding in one hour was $70.18 \%$. (Table 1) gives demographic information of the women in the context of breastfeeding. The mean of age of women was 24.2 (SD $=4.69$ ) years. More than half $(54.51 \%)$ were in the age group of $21-25$ and only $0.55 \%$ in the age group more than 35 years. More than fifty percent $(52.17 \%)$ were 10 th or 12 th pass and only $8.25 \%$ of women were illiterate. Most of the women $(90.63 \%)$ were not formally employed. The proportion of urban women was more than twothirds.
The details of obstetrics factors and initiation of breastfeeding are given in (Table 2). About 25\% of deliveries were preterm. About $85 \%$ of women were first or second para. The proportion of low-birthweight babies was $10.52 \%$. Among male children, the proportion of EIBF was $69.3 \%$ and among females, it was $71.1 \%$. $\left(\chi^{2}=1.04 ; P=0.31\right)$. Few women $(6.14 \%)$ had associated medical illnesses.

\section{Discussion}

In hospitals varied types of skilled birth attendant and all other paraphernalia is available hence high proportion of timely initiation was expected. Most of the reported studies are surveys or analyses of secondary data. The current study has many unique characteristics. The number of women enrolled in the present study was higher than several studies. It was a multi-site study representing a large population. The information was collected by trained qualified doctors and nurses before discharge, almost eliminating the possibility of recall bias.

Despite the universal recommendation, globally only $40 \%$ of children are breastfed within one hour after birth. (9) Systematic reviews and meta-analysis have revealed that the highest early initiation, about $53 \%$ was observed in low-income countries, about $43 \%$ in upper-middle-income countries, and $31 \%$ in lowermiddle income countries. $(12,13)$ Studies conducted in various countries have reported the prevalence of EIBF ranging from 6.9 to $97.3 \%$. $(2,3,14-21)$ The lowest prevalence was reported from Karachi, Pakistan. The highest prevalence was reported from Saudi Arabia. The study from Pakistan was conducted in a squatter settlement area which may explain the reason for having an abysmally low prevalence of EIBF.

Various studies conducted in India, including the present study, also reported a wide range of prevalence of EIBF from 12.5 to $75 \%$. (11,22-35) The lowest prevalence was observed in North India. The highest prevalence was observed in Union Territory Puducherry in South India. Studies analyzing secondary data have yielded a wide range from 12.5 to $34.4 \%$. $(1,4,26)$ The NFHS 4 survey conducted in 2015-16 reported that in India there was wide variation and the overall proportion of EIBF was only $41.6 \%$. (8) There may be several explanations for this wide variation. The increasing trend that emerged from 19 studies (including the present study) conducted across India is reflected in (Figure 2). Even the overall proportion in India has increased from 
23.4 to $41.6 \%$. (8) The trend is similar in other countries also. However, a study from Namibia needs attention, because the national survey has shown a substantial decline from $82.5 \%$ to $74.9 \%$ from 2000 to 2013. (14) Generally, facility-based studies had shown high prevalence. In communitybased studies including national-level surveys, the surveyors gather past information, hence the extent of recall is difficult to measure. Even facility-based studies, if investigators obtain history, may have the same drawback.

The proportion of EIBF reported in this study is higher than the national and state estimate. Maharashtra state has always better statistics than national. $(8,36)$ In the Pune district, EIBF proportions in the last but one national-level survey was $62.0 \%$; (37) it reduced to 54.8.(10) Although the observed proportion in the present study is higher, authors expected very high proportion for two reasons; the present study is comparatively recent and conducted in hospitals. EIBF is a product of the socio-cultural environment. A high proportion of $68 \%$ in the tribal area has been reported.(6) The lowest prevalence in a city from North India (38) and the highest prevalence from a city in South India (34) has been reported. This may be a reflection of higher female literacy and matrimonial hierarchy in Southern India. But one study from Chandigarh has reported a high prevalence of $72.6 \%$ like in South India.(29)

Data given in (Table 1), indicated that the best enabler age group was 20-25 years and most impeding was 30-35 years; however, the strength of association was not significant. In various studies reporting age-wise variation highest prevalence ranged from $45.0-85.1 \%$ and the lowest prevalence ranged from $12.8 \%-37.9 \%$. The highest prevalence in these studies was reported from 20-33 years (excepting one study) and the lowest prevalence among 15-24 years or more than 30 years. $(11,16,34,39)$ Most of the studies thus confirm that the prevalence of EIBF is less in extremes of age group and higher among age group 21 to 30 years. But in Namibia prevalence was about two times higher among women from 15-19 years. (14) This bimodal age distribution may be due to lack of experience and less preparedness among young ladies and a slightly careless attitude in elderly mothers.

According to the current study, secondary school certificate passing enabled women to practice EIBF. Minimal education was an impeder. There are very dissimilar observations reported by different studies. In a neighboring country, various levels of education of women did not affect prevalence which was about $69 \%$ across education groups. (16) Like our study, a high prevalence of $85 \%$ was reported among women having secondary school education (34). In the tribal population women having more than primary schooling had a prevalence of $73 . \%$ and less educated had $46.3 \%$. (6) One secondary analysis revealed that the proportion was twofold among women having education compared to illiterate. (26) Probably educated mothers have some information and access to substitute foods and they might use it, and practice early breastfeeding to a lesser extent. (14)

[Table 1] indicates that professional occupation is the greatest impeding factor in the present study. Most facilitating occupations were small shop keeper and clerical work followed by unemployment. In another study, EIBF was better among employed women (77.9\%) than nonemployed $(22.1 \%)$, including daily wage earners (86.3\%) and lowest (66.7\%) in businesswomen. (34) Employed women initiated early breastfeeding in a higher proportion compared to non-employed but the difference was slight. (16) In an African country, the highest prevalence was noted among agricultural workers. (14)

Although it is believed that place of residence doesn't matter; (9) in the present study residence of women in rural areas was a very positive influential factor. Even in African countries, Zimbabwe and Namibia rural women were more likely to initiate early breastfeeding compared to urban women. $(14,15)$ But in only one study the prevalence was higher among urban women than rural women. (11) Across the countries, EIBF is categorically lower among cesarean-delivered women than vaginally delivered. (9) We also confirmed that cesarean section was one of the factors contributing to the delay in the early initiation of breastfeeding. This observation is almost universal. $(17,21,34,39-41)$ In the studies, the remarkable difference between the prevalence of EIBF among vaginally delivered women (65 to $85 \%$ ) and cesarean delivered women $(14-15 \%)$ is observed. $(11,20)$ Women admit that because of the cesarean section they did not feed the newborn within an hour. (19) Cesarean section is a hindering factor in African and South Asian countries also. $(14,15,42)$ Even in hospitals including a designated Baby-Friendly Hospital in a developed 

country like Australia, there was a persistent barrier to initiation of early breastfeeding among cesarean delivered women. (43) However; another metaanalysis mentioned that cesarean delivery may not be a risk factor of EIBF in the presence of passable support. (44) It is essential to encourage and support EIBF in all mothers irrespective of the mode of delivery and to educate all prospective mothers and health care staff about the negative effects of cesarean delivery on breastfeeding and the wellbeing of the infant. Counseling has resulted in a remarkable change in EIBF practices. (38)

Almost similar to the present study, a larger proportion of full-term newborns (71.7\%) received earlier breastfeeding compared to pre-term (65.10\%) in Bangladesh. (16) Contrarily in one study, the prevalence of EIBF was higher (81.1\%) when the outcome is preterm newborn compared to full term (70.2\%).(34) This finding is contradictory to our study. The difference may be due to the setting of the referred study. It was conducted in a rural area and was a survey.

The proportion of initiating early breastfeeding amongst first paras is usually lower than multiparous women. In various Indian studies, including the present study the prevalence among first paras varied, from 32.5 to $65.8 \%$; and the prevalence among multiparous varied from 56.9 to $81.5 \%$, including the present study.(11,32) In other countries also multipara was more likely to initiate early breastfeeding first para.(11) Multiparity was enabling factor in Namibia and Zimbabwe also. $(14,15)$

We observed that mothers having newborns with birth weight greater than $2.5 \mathrm{~kg}$ have a higher prevalence (72.4\%) of EIBF as compared to newborns with birth weight lesser than $2.5 \mathrm{~kg}$ (73.9\%). A higher proportion, about $42 \%$ newborn weighing $2.5 \mathrm{~kg}$ or more received breastfeeding within one hour while weighing less, only $30 \%$ received.(11) Another study conducted in Saudi Arabia showed a higher prevalence $(49 \%)$ among newborns with low birth weight $<2.5 \mathrm{~kg}$ as compared to newborns $(43 \%)$ with birth weight $>2.5 \mathrm{~kg}$.(20) Low birth weight as well macrosomia resulted in delaying initiation of breastfeeding. $(14,15)$ The size of the baby is a proxy of birth weight.

Although some studies reported differential prevalence for gender; the prevalence among male and female newborns was similar in the present study. Globally also it is observed that the sex of the newborn doesn't matter.(9)

About $10.7 \%$ of the mothers reported that due to some sickness they did not initiate breastfeeding early.(20) Women gave many reasons for not initiating breastfeeding earlier; even hypertension was one of the reasons given for not initiating breastfeeding early.(19) Mothers having some medical problems like sore nipple, cracked nipple and inverted nipple were less likely to initiate early breastfeeding.(22)

\section{Conclusion}

The main impeders for ElBF were the cesarean section and the residence in the urban area. Increasing cesarean sections may pose risk to the enhancement of EIBF. The most likely reason seems to be sub-optimal awareness among the health staff as well as the mothers. The observations reiterate the need for expansion, monitoring, and reaccreditation of Baby-Friendly Hospital Initiative as well as other breastfeeding promotion programs. There is a strong need to strengthen the national and state policies, hospital and maternity practices, and the knowledge of all the categories of skilled birth attendants, to support EIBF as a key component of essential new-born care. The studies have shown that barriers are not insurmountable. Behavior Change Communication certainly and substantially improve the prevalence. The communication may be specially targeted to pregnant mothers throughout the peripartum period particularly women undergoing cesarean section, residents of urban areas.

\section{Recommendation}

All health workers must provide information about necessity of early initiation of breastfeeding to all women during antenatal visits and especially to those who are from urban areas and cesarean delivered.

\section{Limitation of the study}

The study had some limitations. Few forms received from various centers had incomplete data. Adherence to the skin-to-skin care practice was not studied. The comparison is between the two groups is valid but overall results may be slightly skewed; as in the population, the proportion of cesarean section is not $50 \%$. 


\section{Relevance of the study}

Cesarean delivery is a strong barrier for initiation of early breastfeeding.

\section{Authors Contribution}

Conceptualization and design: PPD, VMV, AVP. Data acquisition and monitoring: PPD, VMV, APSN, CNW, TMP, AVP. Analysis and interpretation: PPD, VMV. Initial drafting the article: VMV. Final draft: PPD, AVP. Critical review by all authors. Final draft of the article was approved by all authors.

\section{Acknowledgement}

We sincerely thank the study participants, all medical and paramedical personnel as well as administrative authorities of selected study centers. Special thanks to statistician Mr. Shrivallabha Sane from Department of Community Medicine, Dr. Ramesh Bhosale, Dr. Aparna Shrotri. We thank UNFPA and Government of Maharashtra for financial support.

\section{References}

1. Phukan D, Ranjan M, Dwivedi LK. Impact of timing of breastfeeding initiation on neonatal mortality in India. Int Breastfeed J. 2018;13:27. doi: 10.1186/s13006-018-0162-0. PMID: 29988694; PMCID: PMC6029033.[PubMed].

2. Edmond KM, Zandoh C, Quigley MA, Amenga-Etego S, Owusu-Agyei S, Kirkwood BR. Delayed breastfeeding initiation increases risk of neonatal mortality. Pediatrics. 2006;117(3):e380-6. doi: 10.1542/peds.2005-1496. PMID: 16510618. [PubMed].

3. NEOVITA Study Group. Timing of initiation, patterns of breastfeeding, and infant survival: prospective analysis of pooled data from three randomised trials. Lancet Glob Health. 2016;4(4):e266-75. doi: 10.1016/S2214109X(16)00040-1. PMID: 27013313. [PubMed].

4. Aguayo VM, Gupta G, Singh G, Kumar R. Early initiation of breast feeding on the rise in India. BMJ Glob Health. 2016;1(2):e000043. doi: 10.1136/bmjgh-2016-000043. PMID: 28588936; PMCID: PMC5321339.[PubMed].

5. Sutan R, Berkat S. Does cultural practice affects neonatal survival- a case control study among low birth weight babies in Aceh Province, Indonesia. BMC Pregnancy Childbirth. 2014;14:342. doi: 10.1186/1471-2393-14-342. PMID: 25269390; PMCID: PMC4262197.[PubMed]

6. Sankar MJ, Neogi SB, Sharma J, Chauhan M, Srivastava R, Prabhakar PK, Khera A, Kumar R, Zodpey S, Paul VK. State of newborn health in India. J Perinatol. 2016;36(s3):S3-S8. doi: 10.1038/jp.2016.183. PMID: 27924104; PMCID: PMC5144119.[PubMed].

7. International Institute for Population sciences. National Family Health Survey - 5 2019-20. State Fact Sheet, Maharashtra. 2020.

8. International Institute for Population Sciences. National Family Health Survey -4, 2015-16: India Fact Sheet. Vol. I. 2017. Available from: http://www.measuredhs.com/pubs/pdf/FRIND3/00Front Matter00.pdf.
UNICEF WHO. Capture the moment-Early initiation of breastfeeding: The bet starrt for every newborn. 2018. p. 44.

10. International Institute for Population sciences, Ministry of Health and Family Welfare G of I. National Family Health Survey - 5 District Fact Sheet Pune. 2020.

11. Badaya N, Jain S, Kumar N. Time of initiation of breastfeeding in various modes of delivery and to observe the effect of low birth weight and period of gestation on initiation of breastfeeding. Int J Contemp Pediatr. 2018;5(4):1509.

12. Sharma IK, Byrne A. Early initiation of breastfeeding: a systematic literature review of factors and barriers in South Asia. Int Breastfeed J. 2016;11:17. doi: 10.1186/s13006016-0076-7. PMID: 27330542; PMCID: PMC4912741.[PubMed]

13. Victora CG, Bahl R, Barros AJ, França GV, Horton S, Krasevec J, Murch S, Sankar MJ, Walker N, Rollins NC; Lancet Breastfeeding Series Group. Breastfeeding in the 21st century: epidemiology, mechanisms, and lifelong effect. Lancet. 2016;387(10017):475-90. doi: 10.1016/S01406736(15)01024-7. PMID: 26869575.[PubMed].

14. Ndirangu MN, Gatimu SM, Mwinyi HM, Kibiwott DC. Trends and factors associated with early initiation of breastfeeding in Namibia: Analysis of the Demographic and Health Surveys 2000-2013. BioMed Cent Pregnancy Childbirth. 2018;18(1):1-10. Available from: http://www.embase.com/search/results?subaction=viewr ecord\&from=export\&id=L622142688\%0Ahttp://dx.doi.org /10.1186/s12884-018-1811-4.

15. Mukora-Mutseyekwa F, Gunguwo H, Mandigo RG, Mundagowa P. Predictors of early initiation of breastfeeding among Zimbabwean women: secondary analysis of ZDHS 2015. Matern Health Neonatol Perinatol. 2019;5:2. doi: 10.1186/s40748-018-0097-x. PMID: 30675366; PMCID: PMC6332660.[PubMed].

16. Karim F, Billah SM, Chowdhury MAK, Zaka N, Manu A, Arifeen SE, Khan ANS. Initiation of breastfeeding within one hour of birth and its determinants among normal vaginal deliveries at primary and secondary health facilities in Bangladesh: A case-observation study. PLoS One. 2018;13(8):e0202508. doi: 10.1371/journal.pone.0202508. PMID: 30114288; PMCID: PMC6095597.[PubMed].

17. Chen C, Yan Y, Gao X, Xiang S, He Q, Zeng G, Liu S, Sha T, Li L. Influences of Cesarean Delivery on Breastfeeding Practices and Duration: A Prospective Cohort Study. J Hum Lact. 2018;34(3):526-534. doi: 10.1177/0890334417741434. Epub 2018 Jan 24. PMID: 29365288. [PubMed].

18. Beyene MG, Geda NR, Habtewold TD, Assen ZM. Early initiation of breastfeeding among mothers of children under the age of 24 months in Southern Ethiopia. Int Breastfeed J. 2017;12:1. doi: 10.1186/s13006-016-0096-3. PMID: 28070207; PMCID: PMC5217403.[PubMed]

19. Badruddin SH, Inam SN, Ramzanali S, Hendricks $K$. Constraints to adoption of appropriate breast feeding practices in a squatter settlement in Karachi, Pakistan. J Pak Med Assoc. 1997;47(2):63-8. PMID: 9071864.[PubMed].

20. Ahmed AE, Salih OA. Determinants of the early initiation of breastfeeding in the Kingdom of Saudi Arabia. Int Breastfeed J. 2019;14:13. doi: 10.1186/s13006-019-0207-z. PMID: 30984282; PMCID: PMC6444675.[PubMed]. 
INDIAN JOURNAL OF COMMUNITY HEALTH / VOL 33 / ISSUE NO 01 / JAN- MAR 2021

21. Paksoy Erbaydar N, Erbaydar T. Relationship between caesarean section and breastfeeding: evidence from the 2013 Turkey demographic and health survey. BMC Pregnancy Childbirth. 2020;20(1):55. doi: 10.1186/s12884020-2732-6. PMID: 31992238 ; PMCID: PMC6988204.[PubMed].

22. Kalaivani A, Garg MD, Rao MS. Cross-sectional study of the breastfeeding practices among women delivering in a tertiary care hospital in Puducherry, India. Int J Contemp Pediatr. 2019;6(3):945.

23. Sarkar $T$, Bhattacherjee $S$, Mukherjee A, Saha $T$, Chakraborty M, Dasgupta S. Early initiation of breast feeding in tribal children. Int J Community Med Public Heal. 2016;3(11):3081-5.

24. Shaili V, Parul S, Kandpal SD, Jayanti S, Anurag S, Vipul N. A community based study on breastfeeding practices in a rural area of Uttarakhand. Natl J Community Med. 2012;3(2):283-7. Available from: http://njcmindia.org/uploads/3-2 283-287.pdf .

25. Uppiretla SB, Mishra SK, Rachakulla HK. Infant feeding practices among mothers in rural Rajamahendravaram, Andhra Pradesh. Int J Community Med Public Heal. 2019;6(5):2121.

26. Patel A, Banerjee A, Kaletwad A. Factors associated with prelacteal feeding and timely initiation of breastfeeding in hospital-delivered infants in India. J Hum Lact. 2013;29(4):572-8. doi: 10.1177/0890334412474718. Epub 2013 Feb 20. PMID: 23427115. [PubMed].

27. Athavale A V. Initiation of Breast-feeding by urban women. Heal Popul Issues. 2004;27(2):117-25.

28. Bandyopadhyay M. Impact of ritual pollution on lactation and breastfeeding practices in rural West Bengal, India. Int Breastfeed J. 2009 Mar 26;4:2. doi: 10.1186/1746-4358-42. PMID: 19323839; PMCID: PMC2667394.[PubMed].

29. Dhiman, A., Goel, N.K., Singh, N. and Galhotra A. Breast Feeding Practices and Associated Veriables in Chandgarh Tricity, India. Int J Curr Res. 2016;8(8):37291-5.

30. Dihidar S, Bhattacharya BN, Mukherjee KL. Description of breastfeeding practices among poorer sections in Calcutta Metropolitan Area and its impact on postpartum infecundity. J Child Health Care. 2002;6(3):203-19. doi: 10.1177/136749350200600301.

PMID: 12224837. [PubMed].

31. Khan $\mathrm{M}$, Khalique $\mathrm{N}$, Siddiqui A, Amir A. Newborn care practices amon slum dwellers in Aligarh City, Uttar Pradesh. Indian J Community Heal. 2013;25(1):28-33.

32. Mise PJ, Mise AJ, Mise SJ, Siddappa M. Study of breastfeeding practices and problems among postnatal mothers: a hospital based study. Int J Reprod Contraception, Obstet Gynecol. 2017;6(8):3343.

33. Patel A, Badhoniya N, Khadse S, Senarath U, Agho KE, Dibley MJ; South Asia Infant Feeding Research Netwoork. Infant and young child feeding indicators and determinants of poor feeding practices in India: secondary data analysis of
[Comparative Study...] | Vaidya VM et al National Family Health Survey 2005-06. Food Nutr Bull. 2010;31(2):314-33. doi: 10.1177/156482651003100221. PMID: 20707236.[PubMed]

34. Prasad K, Ahamed N. Community based study on initiation of breast feeding and determining factors in rural area of Pondicherry. Int J Contemp Pediatr. 2015;2(3):208-12.

35. Swetha R, Ravikumar J, Rao R $\mathrm{n}$. Study of breastfeeding practices in coastal region of South India: a cross sectional study. Int J Contemp Pediatr. 2014;1(2):1.

36. International Institute for Population sciences. National Family Health Survey - 4 2015-16. State Fact Sheet, Maharashtra. 2015. Available from: http://rchiips.org/nfhs/pdf/NFHS4/GJ FactSheet.pdf .

37. International Institute for Population Sciences. National Family Health Survey - 4, 2015-16, District Fact Sheet Pune Maharashtra. 2017.

38. Khan $\mathrm{MH}$, Khalique $\mathrm{N}$, Siddiqui $\mathrm{A}$, Amir A. Breastfeeding Practices in Periurban Area of Aligarh- A Community Based Study. Natioanl J Res Community Med. 2012;1(4):178-241.

39. Gedefaw G, Goedert MH, Abebe E, Demis A. Effect of cesarean section on initiation of breast feeding: Findings from 2016 Ethiopian Demographic and Health Survey. PLoS One. 2020;15(12):e0244229. doi: 10.1371/journal.pone.0244229. PMID: 33338080; PMCID: PMC7748140. [PubMed]

40. Takahashi K, Ganchimeg T, Ota E, Vogel JP, Souza JP, Laopaiboon M, Castro CP, Jayaratne K, Ortiz-Panozo E, Lumbiganon $P$, Mori R. Prevalence of early initiation of breastfeeding and determinants of delayed initiation of breastfeeding: secondary analysis of the WHO Global Survey. Sci Rep. 2017;7:44868. doi: 10.1038/srep44868. PMID: 28322265; PMCID: PMC5359598. [PubMed].

41. Prior E, Santhakumaran S, Gale C, Philipps LH, Modi N, Hyde MJ. Breastfeeding after cesarean delivery: a systematic review and meta-analysis of world literature. Am J Clin Nutr. 2012;95(5):1113-35. doi: 10.3945/ajcn.111.030254. Epub 2012 Mar 28. PMID: 22456657. [PubMed].

42. Singh $K$, Khan SM, Carvajal-Aguirre $L$, Brodish $P$, Amouzou A, Moran A. The importance of skin-to-skin contact for early initiation of breastfeeding in Nigeria and Bangladesh. J Glob Health. 2017;7(2):020505. doi: 10.7189/jogh.07.020505. PMID: 29423182; PMCID: PMC5804505.[PubMed].

43. Rowe-Murray HJ, Fisher JR. Baby friendly hospital practices: cesarean section is a persistent barrier to early initiation of breastfeeding. Birth. 2002;29(2):124-31. doi: 10.1046/j.1523-536x.2002.00172.x. PMID: 12000413. [PubMed]

44. Rollins NC, Bhandari N, Hajeebhoy N, Horton S, Lutter CK, Martines JC, Piwoz EG, Richter LM, Victora CG; Lancet Breastfeeding Series Group. Why invest, and what it will take to improve breastfeeding practices? Lancet. 2016;387(10017):491-504. doi: 10.1016/S01406736(15)01044-2. PMID: 26869576.[PubMed]. 


\section{Tables}

TABLE 1 SOCIO-DEMOGRAPHIC AND OBSTETRIC CHARACTERISTICS OF STUDY PARTICIPANTS, 2017-18

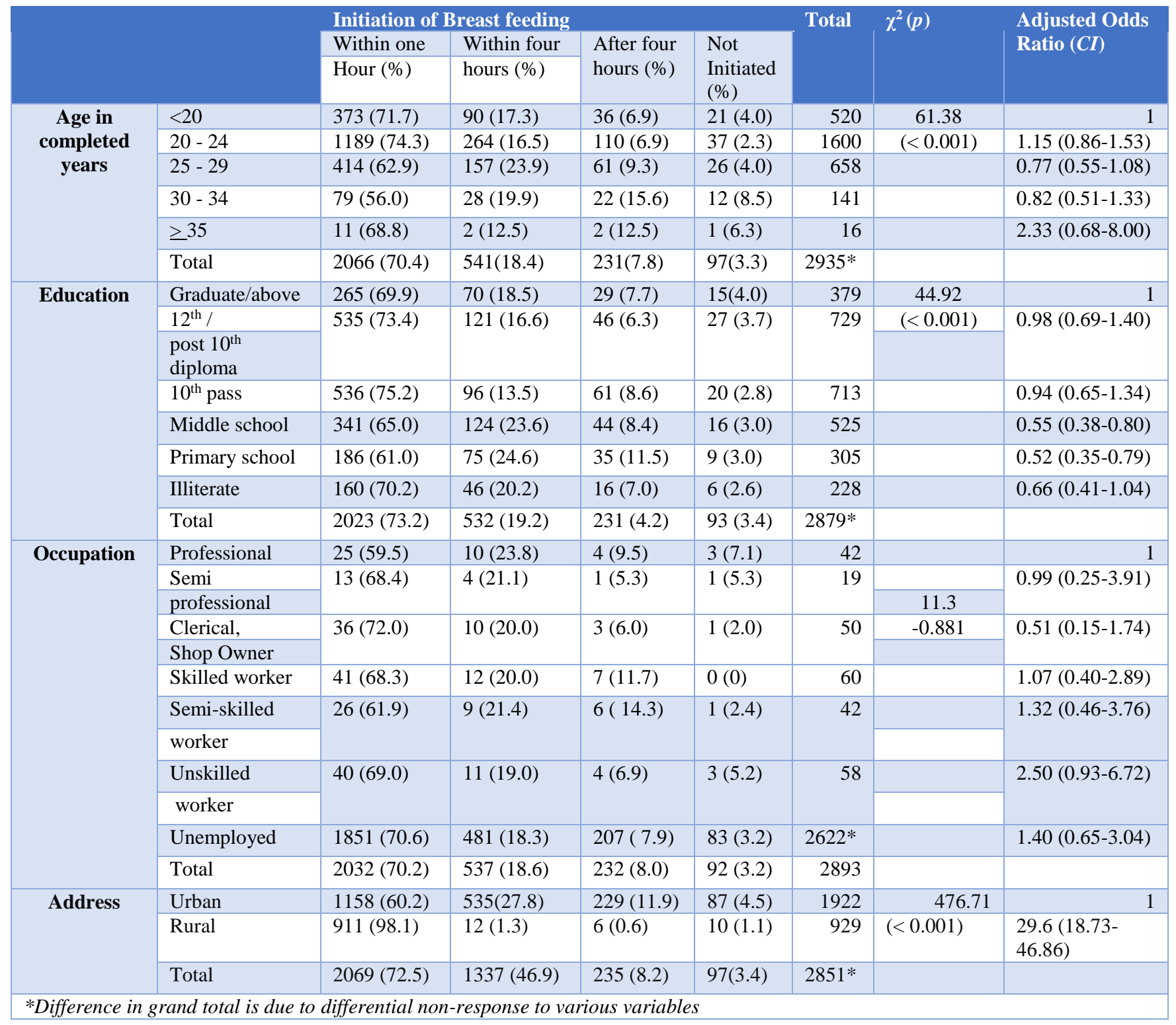

\section{TABLE 2 OBSTETRIC FACTORS AND INITIATION OF BREAST FEEDING, 2017-18}

\begin{tabular}{|c|c|c|c|c|c|c|c|c|}
\hline & & \multicolumn{4}{|c|}{ Initiation of Breast feeding } & \multirow[t]{2}{*}{ Total } & \multirow[t]{2}{*}{$\chi^{2}(p)$} & \multirow{2}{*}{$\begin{array}{l}\text { Adjusted Odds } \\
\text { Ratio (CI) }\end{array}$} \\
\hline & & $\begin{array}{l}\text { Within one } \\
\text { Hour }(\%)\end{array}$ & $\begin{array}{l}\text { Within four } \\
\text { hours }(\%)\end{array}$ & $\begin{array}{l}\text { After four } \\
\text { hours }(\%)\end{array}$ & $\begin{array}{l}\text { Not Initiated } \\
(\%)\end{array}$ & & & \\
\hline \multirow{4}{*}{$\begin{array}{l}\text { Gestational age } \\
\text { (weeks) }\end{array}$} & $<32$ & $17(33.3)$ & $11(21.6)$ & $6(11.8)$ & $17(33.3)$ & 51 & 216.36 & 1 \\
\hline & $32-37$ & $432(65.5)$ & $103(15.6)$ & $85(12.9)$ & $40(6.1)$ & 660 & $(<0.001)$ & $2.60(1.22-5.52)$ \\
\hline & $>37$ & $1558(72.6)$ & $414(19.3)$ & $137(6.4)$ & $37(1.7)$ & 2146 & & $3.41(1.62-7.16)$ \\
\hline & Total & $2007(70.2)$ & $528(18.5)$ & $228(8.0)$ & $94(3.3)$ & $2857 *$ & & \\
\hline \multirow[t]{5}{*}{ Parity } & Primipara & $762(65.8)$ & $263(22.7)$ & $133(11.5)$ & $51(4.4)$ & 1209 & 53.46 & 1 \\
\hline & $2^{\text {nd }}$ Para & $920(75.8)$ & $220(18.1)$ & $74(6.1)$ & $34(2.8)$ & 1248 & $(<0.001)$ & $1.44(1.16-1.80)$ \\
\hline & $3^{\text {rd }}$ Para & $301(79.6)$ & $54(14.3)$ & $23(6.1)$ & $11(2.9)$ & 389 & & $1.71(1.20-2.43)$ \\
\hline & Multipara & $22(81.5)$ & $04(14.8)$ & $01(3.7)$ & $01(3.7)$ & 28 & & $1.70(0.58-4.96)$ \\
\hline & Total & $2005(69.8)$ & $541(18.8)$ & $231(8.0)$ & $97(3.4)$ & $2874 *$ & & \\
\hline \multirow[t]{2}{*}{ Birth Weight } & $<2.5$ & $212(73.9)$ & $43(15.0)$ & $32(11.1)$ & $23(8.0)$ & 310 & 24.6 & 1 \\
\hline & $\geq 2.5$ & $1857(72.4)$ & $504(19.7)$ & 203 (7.9) & $74(2.9)$ & 2638 & $(<0.001)$ & $0.97(0.70-1.36)$ \\
\hline
\end{tabular}




\begin{tabular}{|l|l|l|l|l|l|r|r|r|}
\hline \multirow{2}{*}{$\begin{array}{l}\text { Mode of } \\
\text { Delivery }\end{array}$} & Total & $2069(70.2)$ & $547(18.6)$ & $235(8.0)$ & $97(3.3)$ & $2948^{*}$ & 174.41 & \\
& VSCS & $902(63.6)$ & $320(22.6)$ & $197(13.8)$ & $69(4.8)$ & 1488 & 1 \\
\cline { 2 - 9 } & Vaginal & $1167(81.5)$ & $227(15.8)$ & $38(2.6)$ & $28(1.9)$ & 1460 & $(<0.001)$ & $3.26(2.66-3.99)$ \\
\cline { 2 - 9 } & Total & $2069(70.2)$ & $547(18.6)$ & $235(8.0)$ & $97(3.3)$ & $2948^{*}$ & \\
\hline \multirow{2}{*}{$\begin{array}{l}\text { Associated } \\
\text { Medical illness }\end{array}$} & Yes & $84(50.9)$ & $53(32.1)$ & $28(17.0)$ & $16(9.7)$ & 181 & 59.13 & \\
\cline { 2 - 9 } & No & $1985(73.9)$ & $494(18.4)$ & $207(7.7)$ & $81(3.0)$ & 2767 & $(<0.001)$ & $1.86(1.28-2.71)$ \\
\cline { 2 - 9 } & Total & $2069(70.2)$ & $547(18.6)$ & $235(8.0)$ & $97(3.3)$ & $2948^{*}$ & \\
\hline \multirow{2}{*}{ *Difference in grand total is due to differential non-response to various variables } &
\end{tabular}

\section{Figures}

FIGURE 1 SELECTED HOSPITALS IN PUNE DISTRICT, 2017-18

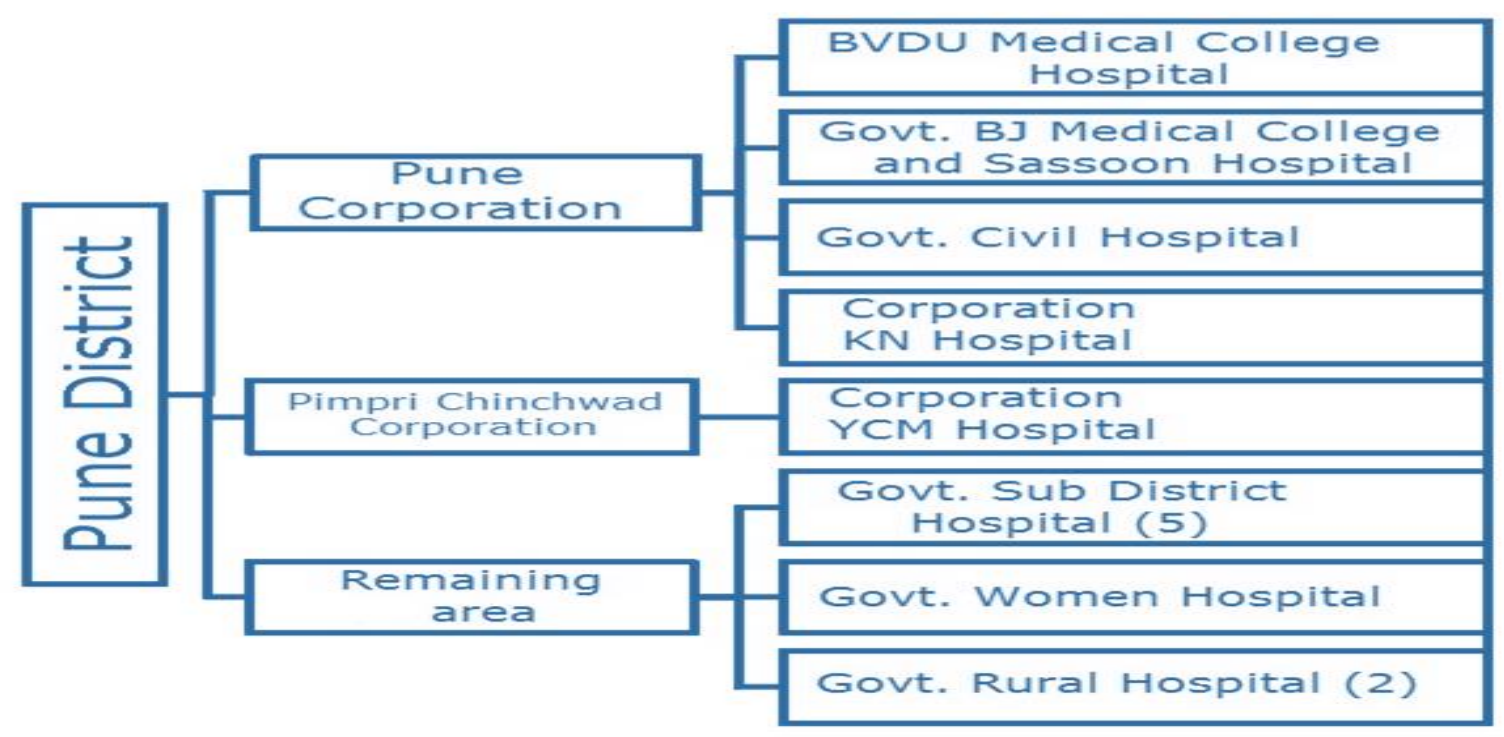

FIGURE 2 TREND OF EIF IN INDIA, 1994-2018

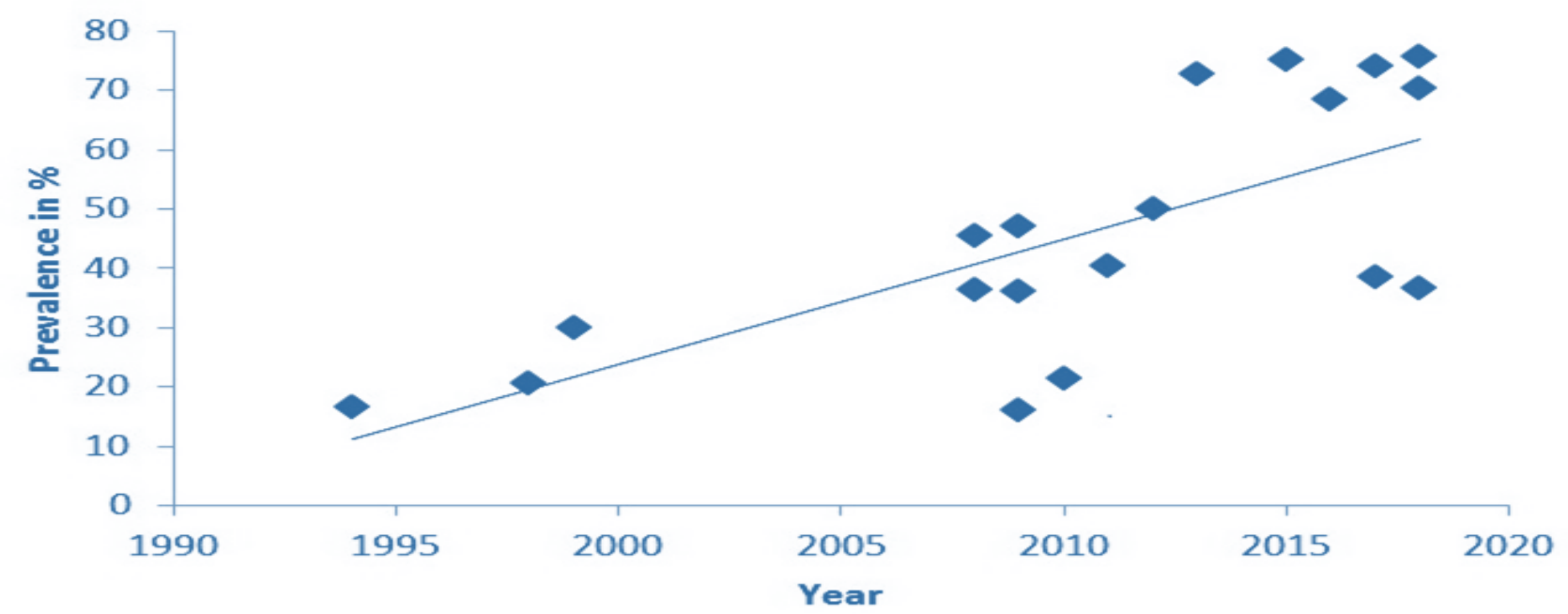

